\title{
VALORI SEMANTICO-PRAGMATICE ALE APOZIȚIEI ÎN LIMBA ROMÂNĂ VORBITĂ
}

\begin{abstract}
Rozalia COLCIAR*
Semantic-Pragmatic Values of Apposition in Spoken Romanian

Abstract: The study approaches the apposition and the means of expressing the appositive relationship in spoken Romanian based on the material extracted from the published spoken language corpora (CORV, IV II and ROVA) which best illustrate the everyday discourse. The appositive relationship is a relatioships of discoursive equivalence between two coreferential linguistic sequences: basis (actual reference) and apposition (virtual reference). The apposition states another feature of the referee characterized by the first term in the commnunication, resuming and completing it. From the pragmatic point of view, the apposition is also a speech act, a discoursive strategy, marking the interrupted message in the form of a supplementary element through which the locutor doubles the first denomination. According to the classifications proposed by GALR II, we study, at clause and senttence levels, the nominal appositions (equative or attributive types), the appositive structures simple or complex (chained), resumative or multiple (analytic) and also semantic types of appositions (identifying, designating or rephrasing). We are going to identify the appositive structures marked by apposemes (adverbs having a metalinguistic function, whose role is to explain the appositive relationship), such as: adică (such as), și anume (namely), altfel spus (in other words), mai bine zis (better said), mai exact (more exactly), respectiv (i.e.).
\end{abstract}

Keywords: spoken language, apposition, appositive relationship, coreferenciality, discoursive strategy.

\section{Considerații teoretice}

În lingvistica românească, apoziţia și raportul apozitiv au stat sub semnul controverselor interpretative.

Abordările tradiționale tratează apoziția din perspectiva raportului de subordonare, de dependenţă, considerând-o ca o unitate sintactică, o variantă de realizare a atributului, respectiv ,,atribut substantival, indiferent de cazul termenului determinat sau acordat în caz cu acesta"1. Alte abordări interpretează apoziția prin prisma relației sintactice de nondependență, în

\footnotetext{
* Cerc. şt. II dr., Institutul de Lingvistică și Istorie Literară „Sextil Pușcariu” al Academiei Române din Cluj-Napoca, str. Racoviță,nr. 21, Cluj-Napoca (rozaliac@yahoo.com).

${ }^{1}$ GLR II 1966: 128.

${ }^{2}$ Guțu Romalo 1973: 41-45, Teodorescu 1974: 5-8, LRC 1978: 632.
} 
cadrul căreia termenii implicaţi se află într-un raport de echivalență referențială și sintactică ${ }^{3}$.

Abordări mai recente ${ }^{4}$ susțin teza excluderii apoziției din rândul funcțiilor sintactice ${ }^{5}$, considerând-o ca subsumabilă unei categorii sintactice distincte: „nonfuncţia”, alături de subiect și de nominalul în vocativ. Argumentul acestei teze este acela că apoziția este o construcție sintactică lipsită, în orice context, de mărcile specifice oricărui tip de relație sintactică și, prin însuși faptul de a se situa între paranteze, nu actualizează valențe.

Din perspectivă semantică, relația de apoziție este văzută ca o relație de ,adordonare”, alături de coordonare, expresie a unui raport nesintagmatic, în afara relațiilor de tip cazual ${ }^{6}$ sau ca ,expresia sintactică a intersectării a două sau mai multe perspective semantice din care este interpretată la un moment dat o aceeași realitate extralingvistică" ${ }^{\prime \prime}$. C. Dimitriu $^{8}$ susține că între apoziţie și antecedentul ei nu există sinonimie sintactică și, uneori, nici lexicală, deși acești termeni presupun o singură noțiune. Vorbitorul „traduce” baza pentru interlocutor printr-o apoziție, putând apoziționa cu informație semantică orice termen al codului.

Din punct de vedere semantic, apoziția și baza (sau suportul ei) sunt coreferențiale: primul termen al sintagmei, baza, introduce un referent în discurs, iar apoziția, ca al doilea termen, îl reia, dublându-l. Baza are deci funcția de a identifica referentul, iar apoziţia, de a oferi detalii despre caracteristicile bazei, funcționând ca un ,predicat semantic secundar"9.

Din punct de vedere pragmatic, între apoziție și baza ei se stabilește o relație de echivalență discursivă, realizată prin activarea unor posibilităta semantice, virtual prezente în matricea termenului. Potrivit GALR II ${ }^{10}$, opinie căreia ne raliem și noi, sintagma apozitivă este un fapt lingvistic eminamente discursiv, un act de limbaj și o strategie discursivă, ea marcând o întrerupere a mesajului sub forma unui element suplimentar prin care locutorul dublează prima denumire. Același referent este introdus în enunț din două sau mai multe perspective diferite. Apoziția (referință virtuală) precizează o altă caracteristică a referentului introdus în comunicare prin primul termen (referință actuală), pe care îl reia și îl completează.

\footnotetext{
${ }^{3}$ Sunt abordări specifice sintaxei de tip structural. Cf. și DSL 2005: 64-65.

${ }^{4}$ Drașoveanu 1997: 75-76, Neamțu 2004, Pomian 2013: 125.

${ }^{5}$ Ideea apare și la Vulișici Alexandrescu 1995 și la Hodiș 2006: 128 ș.u.

${ }^{6}$ Diaconescu 1989: 127-205.

${ }^{7}$ Irimia1997: 510.

${ }^{8}$ 2002: 1498.

${ }^{9}$ GBLR 2010: 596.

${ }^{10}$ 2005: 620 .
} 


\section{Apoziția în limba română vorbită}

În conformitate cu clasificările propuse de GALR II ${ }^{11}$, vom urmări, în prezenta lucrare, apoziția și modul de exprimare a relației apozitive în limba română vorbită. Materialul ilustrativ folosit în acest demers a fost excerptat din corpusurile de limbă română vorbită publicate: L. Dascălu Jinga, Corpus de română vorbită - CORV, Interacțiunea verbală - IV II și Româna vorbită actuală - ROVA. Considerăm că materialul este reprezentativ pentru discursul cotidian, un tip de discurs caracterizat prin informalitate și familiaritate cu interlocutorul ${ }^{12}$, în care registrul de limbă utilizat este cel colocvial sau al românei vorbite, respectiv „limba vorbită de persoane cu nivel mediu și înalt de instrucție, în situații predominant informale (dar nu numai)"13.

2.1. Din punct de vedere morfosintactic, tiparul apozitiv cel mai frecvent este reprezentat de două nominale coreferenţiale, însă apoziţia poate fi realizată prin orice parte de vorbire sau printr-o propoziție atributivă.

Realizarea prototipică a apoziției este cea nominală, distingându-se două tipuri de apoziții nominale: ecuative și atributive.

2.1.1.Apoziția ecuativă este un predicat secundar postpus bazei, care poate fi substituibil acesteia. Distincția dintre apoziție și bază se realizează doar în funcție de topică, schimbarea acesteia implicând inversarea rolurilor: baza devine apoziție, iar apoziția se transformă în bază:

(1) noi noi făcusem $\downarrow$ eu și cu loredana $\downarrow$ făcusem planu cum să faci sănchizi balconu cu termopan (IV II: 358);

(2) \# numai președintele sau vicepreședintele \#judecătorul de serviciu $\backslash M A R C N U$ primește cereri de \# REAbilitare > (ibidem: 368);

(3) doamna aia care a venit ieri\arhitecta $\uparrow \hat{\imath}$ are pe fi-su $\hat{\imath} \hat{\imath}$ :\# $\hat{\imath} n$ franța (ROVA: 65);

(4) a murit $\uparrow$ a murit. da «aTÂta avere $\downarrow$ un colier și asta $\downarrow$ CINZEJ_DA MII dă euro? (ibidem: 91) ${ }^{14}$.

\footnotetext{
11 2005: 619-631.

12 Acest tip discursiv se caracterizează, după Rovența-Frumuşani (2005: 77), prin următoarele trăsături: apare în situații predominant informale, în planul vieții cotidiene; interlocutorii pot să aibă niveluri diferite de educație și să aparțină unor straturi sociale diferite; utilizează foarte rar specificări și generalizări; are o mare încărcătură afectivă; folosește clișee lingvistice și locuțiuni, evitând cuvintele abstracte, înlocuite prin parafrazări.

${ }^{13}$ Dascălu Jinga 2002: 22.

14 În exemplele citate, am respectat modalitatea de transcriere utilizată de către autorii corpusului respectiv.
} 
În cazul apoziției ecuative, dată fiind perfecta echivalență a termenilor, în absența relației apozitive, oricare dintre cei doi termeni acoperă integral referința termenului introdus în discurs.

2.1.2.Apoziția atributivă este un tip special de predicat secundar apozitiv, obligatoriu postpus bazei și nesubstituibil acesteia. Centrul grupului nominal din cadrul acestei apoziții este numai un substantiv comun nearticulat, dar însoțit, de obicei, de determinanţi:

(1) declarația conținută într-un text fluviu de o oră, cu o vădită intenție de senzație, text citit pe nerăsuflate ca un actor, cititor de texte comandate. (IV II: 418);

(2) Și-a cumpărat o blană de urs polar comandată direct de la Oslô... urs pă care ȘI eu l-am călărit în copilărie (CORV: 117);

(3) E vorba cu alte cuvinte $\uparrow$ de a: /î: cerceta $\uparrow$ trecutul aCElor $/ \hat{\imath}$ : oameni care candidează pentru funcții. importante- $n$ stat $\uparrow$ membri ai Parlamentului $\downarrow$ miniștri $\downarrow$ președinți $\downarrow$ ș-așa mai dăparte. (ibidem: 235).

După cum se poate constata în exemplele citate supra, apoziţia atributivă este realizată printr-un substantiv „,care denotă o proprietate a unui individ"15.

\subsection{Structuri apozitive}

Elementele apozitive pot fi clasificate în funcție de varietatea lexicală și de virtualitățile semantice actualizate în context ${ }^{16}$.

2.2.1. Din punctul de vedere al complexității structurii lexicale, se pot descrie două tipuri de structuri apozitive: (a) apoziția simplă și (b) apoziția complexă sau înlănțuită.

a) Apoziția simplă este reprezentată de structura prototipică, binară, în cadrul căreia baza este explicată printr-o structură dezvoltată, parafrazată sau specificată, elementele componente ale acestei structuri putând fi, opțional, însoțite de determinanți:

(1) în /î: legislatura următoare $\uparrow$ cel care va profera calomnii și inSULte

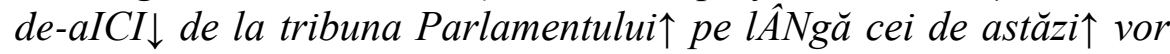
(sic!) fi eXACT Miron Cozma^,eROul” dumneavoastră $\uparrow$ pe care lați încurajat $\uparrow$ și pe care-l stimați atât. (CORV: 279);

(2) \# și când punea masa și tăia o găină $\uparrow \#$ bărBAtului îi dădea copanu [...]partea ceamai bună (ROVA: 71);

\footnotetext{
15 GALR II 2005: 626.

${ }^{16}$ După Irimia (1997: 510), spre deosebire de celelalte relații sintactice, esența apoziției stă în modul specific de dezvoltare a complementarității sintaxă-semantică în actul de comunicare lingvistică.
} 
(3) ăsta $\uparrow$, ,șantieru în lucru” NU este jucat $\downarrow$ pentru că la mijloc era chiar miza asta $\downarrow$ era o casă (ibidem: 27);

(4) aşa ca strămoşii dumneavoastră ardelenii care mergeau la începutu secolu[lui. (IV II: 389).

b) În cazul apoziției complexe sau înlănțuite, baza are o interpretare de tip listă; dintr-o sumă de variabile, sunt extrase, printr-un mecanism de identificare, elementele definitorii pentru entitatea prezentă în discurs:

(1) Vi-l puteți, oare, imagina în postura de șef al statului, factor de echilibru, de mediere intre puterile statului, intre forțele politice, exponent al statului în raport cu societatea civilă? (IV II: 419);

(2) Era hramul bisericii $\uparrow$ < dormeai noaptea la mănăstire $\uparrow$ și-a doua zi

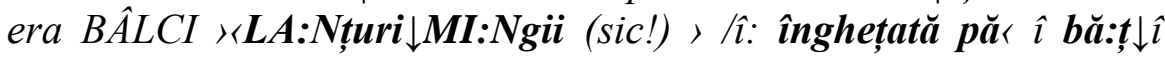
Mere ro:șii $\downarrow$ (CORV: 98-99);

(3) Înainte de emisiune m-a întrebat o tînără colaboratoare douăzeci și de ani o fatăinteligentă $\uparrow$ cultivată $\uparrow$ cu cine va fi studiou. (IV II: $388)$;

(4) lumea-n general citește mai de toate adică și: ă literatură de consum cărțileacelea / denial stil sandra braun (ibidem: 380 ).

În cadrul acestor structuri, apozițiile pot fi atributive, aflate în raport de juxtapunere, precum în exemplele (1) și (2), ecuative - exemplul (3) sau atributivă însoțită de ecuativă - exemplul (4).

2.2.2. După capacitatea apoziţiei de a explicita sau de a sintetiza conținutul informațional al bazei, se disting: (a) apoziţia multiplă sau analitică și (b) apoziția rezumativă (sau sintetică ${ }^{17}$ ).

a) În apoziția multiplă sau analitică, termenul secund, realizat structural ca termen multiplu, analizează, în elementele componente, planul semantic al bazei, care este deci reprezentată ca un întreg:

(1) Vine scursura de-acolo $\uparrow$ sau ce fac ăia. Care fură $\uparrow$ care fac droguri $\uparrow$ care atacă $\uparrow$ care nu știu ce (CORV: 133);

(2) \# am primit mâncare $\uparrow$ venea gustare la ora unsprezece $\uparrow$ \# H $\breve{A L C I}$ de slănină și debrânză și \# ro:șii și ardei și castraveți și Pâinela discreție(ROVA: 95);

(3) Și LÂNgă el este ȘCOAla $\downarrow$ care a fost o casă foarte frumoasă: reședință $\downarrow$ cucoLOAne $\downarrow$ FOARte frumoasă casă (CORV: 71);

(4) șî culorile sînt: FOARti diversificati egzact ca la: Tegola: roșu verdi galben deci toaticulorili cari sînt \# posibile. (IV II: 316).

${ }^{17}$ Irimia 1997: 515. 
Unitățile componente ale apoziției multiple sunt elemente autonome, aflate în raport de coordonare ${ }^{18}$, chiar și atunci când sunt reprezentate de propoziții apozitive, precum în exemplele (1) și (3), care, deși nondependente sintactic de bază, aduc un ,supliment de informație nonrestrictivă" ${ }^{\prime \prime}$.

b) Apoziția rezumativă sau sintetică reia, de obicei printr-un singur termen (termenul secund), o succesiune de unităţi coordonate care reprezintă baza. Acest termen concentrează, în planul său semantic, componentele semantice ale termenului-bază multiplu:

(1) există o LUme țărănească $\downarrow$ există o comuniTAte țărănească $\downarrow$ care este aCEeași $\downarrow$ la NUNȚI $\downarrow$ la boTEzuri $\downarrow$ la MORŢI $\downarrow$ in ocaziile MARI ale vieții (CORV: 181);

(2) în ceea ce privește modernizarea $/ \hat{\imath}:$ locali<î tăților $\uparrow\rangle$ noastre $\downarrow$ trecerea ruralului $\hat{i n}\langle\hat{\imath}$ urban $\downarrow\rangle / \hat{\imath}$ arhitec $\langle\hat{\imath}$ tura $\hat{\imath}\rangle$ rurală $\downarrow\langle s ̧ i$-aşa mai departe $\downarrow$ toate care sunt prezente și care fiecare din ele ar putea constitui un subiect de discuție și de analiză. (ibidem: 185);

(3) B:le spală băile $\downarrow[\ldots]$ io $N$-AȘ face.

A: păi binențeLES. de la câini $\downarrow$ de la pisici de la tot. (ROVA: 111);

(4) B: și-atunci am avut și eu invitați din partea MEA $\downarrow$ a venit și ța:ța $\downarrow$ $o$ venit el:E:na $\downarrow$ (o venit valerică $\downarrow$

A: [toți o fost ai tăi. (ibidem: 175).

Se pot întâlni, ca apoziții cu funcție rezumativă, și apozițiile „profrază ${ }^{, 20}$, în care baza este realizată propoziţional. Aceste apoziții sunt reprezentate de pronumele relativ compus ceea $c e^{21}$ și de demonstrativul cu valoare neutră asta:

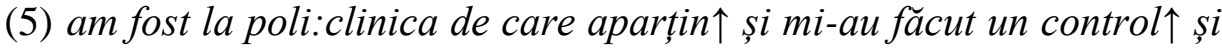
mi-au zis ,a: $\downarrow$ pentru pe stradă NU prea mai aveți nevoie $\uparrow$ < că ați

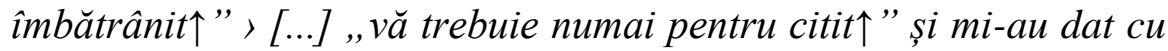
plus [...] ceea ce a fost o nenorocire pentru mine. (ROVA: 39);

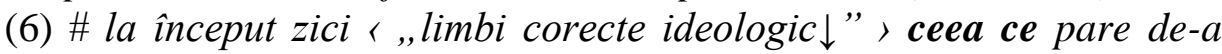
dreptul pozitiv (ibidem: 30 );

\footnotetext{
18 Vezi şi Mircea, Farcaş, „Aspecte privind coordonarea în frază în subdialectul maramureșean“, în Analele Universității din Oradea, Fascicula Limba şi literatura română, Editura Universității din Oradea, p. 167-175.

${ }^{19}$ GALR II 2005: 622.

${ }^{20}$ ibidem: 629.

${ }^{21}$ Este vorba despre „,apoziția relativă/deschisă”, în cazul căreia corespondența semantică se stabilește între primul termen (baza), în toată dezvoltarea lui, și un component al termenului secund, respectiv pronumele relativ cu sens neutru ceea ce, ,prin intermediul căruia se deschide o nouă perspectivă în dezvoltarea planului semantic al propoziţiei apozitive" (Irimia 1997: 511).
} 


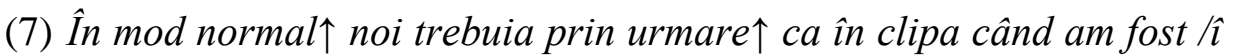

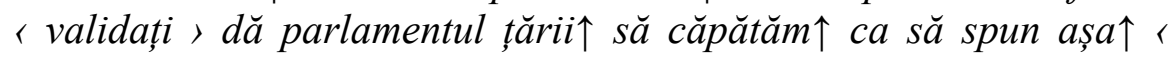
„CHEia”, dă la arhive. Asta e prevăzut în lege. (CORV: 237-238);

(8) Ceea ce s-a inventat și se inventează continuu $\downarrow$ și se perfecționează $\downarrow$ este /̂̀ conTROlul socieTĂții $\downarrow$ 〈,, societății civile” $\downarrow$ 〉 cum spunem noi azi $\uparrow$ asupra celor care se află la putere. Asta este perfecționarea democrației de fapt (ibidem: 272);

(9) și cad continuu în această iluzie. Asta este într-un fel o slăbiciune dar și-n același timp e e o dorință un fel de n-nostalgie inexplicabilă de a mă întoarce. (IV II: 390).

Acest tip de apoziție, cu dezvoltare propoziţională sau frastică, este considerat de către D. Irimia ${ }^{22}$ ca o ,apoziție interpretativă”, care sintetizează planul semantic global al termenului-bază, termenul secund având funcția de subiect într-un nucleu predicațional prin care se interpretează realitatea extralingvistică exprimată de termenul-bază.

\subsubsection{Tipuri semantice de apoziții}

În funcție de relația de echivalență stabilită între bază și termenul secund, se pot delimita, după GALR II $^{23}$, trei tipuri de apoziţii: (a) de identificare, (b) dedesemnare și (c) de reformulare.

a) Apoziția de identificare relevă identitatea realității extralingvistice exprimate prin bază, al cărei conținut semantic este, cel mai frecvent, nedeterminat:

(1) Mai am şi de-alea de: rândul trecut $\downarrow$ de la Casa Veche sau... (CORV: 205);

(2) și E o situație la care guvernul ar trebui să reflecTEze $\downarrow$ aceea a subvenționării(ibidem: 264);

(3) dar eu deci nu mai merg pă: aceASTA: $\downarrow$ < pă pă recurs la executare si merg pă îndreptarea erorii materiale (IV II: 369);

(4) NU-MI place [...] chestia asta $\downarrow$ să obosesc. (ROVA: 150);

(5) persoanele în vîrstă $\downarrow$ pensionari nici ei nu mai știu cîte zile mai au de trăit $\uparrow$ s-apuce să cumpere $\downarrow$ (IV II: 373);

(6) ne-a spus unu din ei $\uparrow$ un tinerel $\uparrow$ Concentrați-vă $\downarrow$ eu acuma am să emit energie. (CORV: 135).

Având în vedere exemplele citate supra, se poate constata faptul că, sub aspect lexico-gramatical, în apoziția de identificare, termenul-bază este reprezentat mai ales printr-un pronume/adjectiv demonstrativ - exemplele

22 1997: 514 .
23 2005: 629. 
(1), (3) și (4), nehotărât - exemplul (6) sau printr-un substantiv abstract exemplele (2), (4) și (5).

b) Apoziția de desemnare ${ }^{24}$ este inversul celei de identificare, termenul secund, mai puțin specific decât baza, realizând o prezentare sau o descriere a realității exprimate prin termenul-bază:

(1) am văzut și prin aeroPORT $\downarrow$ la Paris $\downarrow$ de exemplu $\downarrow$ erau.../a Dulciuri vieneze $\downarrow$ și erau toate astea $\downarrow$ cu Linzer (lințăr) $\downarrow$ cu: tot felul de:...specialități. (CORV: 123);

(2) pentru Profesor $\uparrow / \breve{a}$ institutu ăsta a fost /ă:...biserica dânsului $\downarrow$ adică...ceva: maimult chiar decât faMIlia pot să spun. (ibidem: 161);

(3) B:au făcut ăștia: $\hat{\imath}$ : sînt două SAIturi (=engl. site-uri) \# $\hat{\imath}$ : „pițipoanca” $\uparrow$

A:așa.

B:și , cocalari” \# adică d-ășstia care să dau ei î: importanți $\downarrow$ da sînt neicanimeni $\downarrow$ (ROVA: 66);

(4) La linia de start, s-au aliniat câteva broscuțe, un număr considerabil. (IV II: 427).

c) Apoziția de reformulare ${ }^{25}$ se bazează pe un raport de sinonimie, la nivel lexical sau frastic, fiind o reinterpretare lexicală a bazei:

(1) și-a cumpărat două fotolii de piele roșie $\uparrow$ ălea care mai există la Sohodol. (CORV: 117);

(2) Totuși, cum v-ați dat biografia la întors, cum ați devenit din dușman al americanilor, mâncătorii de oameni, nu-i așa, proamerican? (ibidem: 417);

(3) Activitatea noastră, această meserie, dacă vreți, este, nu numai este că este o meserie nobilă, dar este extrem de asemănătoare cu cea a medicului. (IV II: 432);

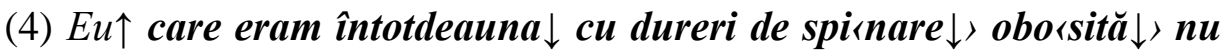
știu ce $\downarrow$ eram dup-o zi foarte grea $\uparrow$ am urcat ca o capră neagră $\uparrow n$ aveam nici pe dracu. (CORV: 142);

(5) vă primim $\downarrow$ acum aici $\uparrow$ în acest loc sfânt al Bisericii noastre $\uparrow c u$ bucuria IMnului biblic Binecuvântat este.Cel ce vine-n numele Domnului $\downarrow$ (ibidem: 281).

\footnotetext{
24 „Apoziție descriptivă”, după Irimia 1997: 513.

25 „Apoziție denominativă” (ibidem).
} 
Exemplele redate ilustrează faptul că ambii termeni ai relației apozitive sunt desemnaţi în acelaşi grad; termenul secund numește realitatea extralingvistică descrisă de termenul-bază sau o decodifică.

\subsubsection{Mărci apozitive}

În enunţ, apoziția poate fi semnalată prin mărci lexico-semantice, prozodice sau grafice.

La nivel lexico-semantic, apoziția poate fi marcată prin apozeme, reprezentate de adverbe/locuțiuni adverbiale cu funcție metalingvistică, având rolul de a explicita relația apozitivă, construcții de tipul adică și anume, mai precis, respectiv, cu alte cuvinte, ca săspunem așa ș.a.:

(1) E dă presupus că...totu să va concentra pă ceea ce în titlul legii să numește deconspirarea activității Securității ca poliție politică $\uparrow$ adică. cercetarea $\downarrow$ istorică $\downarrow$ științifică $\downarrow$ a procerdurilor Securității> a docu〈mentelor rămase de pe urma ei $\downarrow$ (CORV: 240);

(2) l-am /ă reîntîlnit pe: Victor Jinga la: canalu: Dun- (AK) DunăreaMarea Neagră se numea pe-atunci $\uparrow$ la: (AK) ș-anume la: /ă: colonia de muncă Peninsula. (ibidem: 182);

(3) delimitarea limbajului filozofic a fost practic UN DEMERS

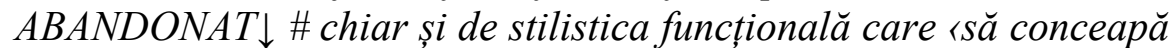
limbajul filozofic ca un produs hibrid situat undeva între limbajul literaturii și cel al științei> ă sau mai precis ca un tip de limbaj științific CARE [...] tinde să-mprumute trăsăturile limbajului literaturii. (IV II: 375);

(4) noi ne adresăm pentru Fiecare problemă celui care le deține $\uparrow$ respectiv deținătorilor dă arhive cunoscuți. (CORV: 238);

(5) Deci SEva Comtimului /î:ca să spunem așa sau 〈PĂRtile BU>ne-ale Comtimului nu s-au exploatat deCÂT numai prin intermediul acestor firme. (ibidem: 265);

(6) A:TOdeauna a fost lumea AȘa. \# ca să ducă o căsnicie $\downarrow$ șaizeci: de

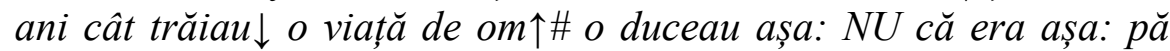
roze $\downarrow$ [...] da trebuia să știe femeia [...].

B: cu alte cuvinte căsniciile:\# mai ales la țară au rezistat zeci de ani datorită înțelepciunii [femeii. (ROVA: 71).

\section{Considerații finale}

Din exemplele de limbă română vorbită analizate, ilustrative pentru discursul oral, se poate deduce faptul că, dincolo de aspectul morfosintactic, aspectul semantico-pragmatic este definitoriu pentru relaţia apozitivă, în cazul căreia unitățile angajate în relație devin echivalente contextual. Apoziția trebuie privită (și) ca un act de limbaj, ca o strategie discursivă cu o anumită intenție de comunicare. Pe lângă aspectul 
informativ și fatic al discursului, se poate decela și un aspect argumentativ al acestuia, bazat pe o intenție persuasivă. Majoritatea enunțurilor citate aparțin unor dialoguri caracterizate printr-o puternică tendință monologică și sunt de tip cooperativ, nonpolemic și nonconflictual (cu o mică excepție: aceea a monologului adresat specific dezbaterilor electorale). Reluările prin reformulare, întâlnite în cadrul relației apozitive, sunt de fapt completări confirmative ale tezei enunţate anterior, menite a provoca reafirmarea sau reconfirmarea opiniei deja existente. Ele susțin discursul și asigură viabilitatea schimbului verbal.

De asemenea, prin caracterul emfatic și afectiv pe care îl implică, apoziția devine, la rândul ei, un mijloc de manifestare a subiectivității în discurs.

\section{ABREVIERI BIBLIOGRAFICE. SIGLE}

\section{a) SURSE:}

CORV = Laurenția Dascălu Jinga, Corpus de română vorbită (CORV). Eșantioane, București, Editura Oscar Print, 2002.

IV II =Interacțiunea verbală (IV II). Aspecte teoretice și aplicative. Corpus, coordonator: Liliana Ionescu-Ruxăndoiu, București, Editura Universității din București, 2007.

ROVA =Româna vorbită actuală (ROVA). Corpus și studii, coord.: Laurenția Dascălu Jinga, București, Editura Academiei Române, 2011.

\section{b) BIBLIOGRAFIE:}

Dascălu Jinga 2002 = Laurenția Dascălu Jinga, Corpus de română vorbită (CORV). Eșantioane, București, Editura Oscar Print.

Diaconescu 1989 = Ion Diaconescu, Probleme de sintaxă a limbii române actuale, București, Editura Științifică și Enciclopedică.

Dimitriu 2002 = Corneliu Dimitriu, Tratat de gramatică alimbii române, vol. II,Sintaxa, Iași, Editura Institutul European.

Drașoveanu 1997 = D. D. Drașoveanu, Teze și antiteze în sintaxa limbii române, Cluj-Napoca, Editura Clusium.

DSL 2005 = Angela Bidu-Vrănceanu et alii, Dicționar de științe ale limbii, București Editura Nemira.

Farcaș 2005 = Ioan-Mircea Farcaş, „Aspecte privind coordonarea în frază în subdialectul maramureșean“, în Analele Universității din Oradea, Fascicula Limba și literatura română, Editura Universității din Oradea, p. 167-175.

GALR II 2005 =Gramatica limbii române II. Enunțul, București, Editura Academiei Române. 
GBLR 2010 =Gramatica de bază a limbii române, Coordonator: Gabriela PanăDindelegan, București, Editura Univers Enciclopedic Gold.

GLR II 1966 =Gramatica limbii române, vol. II, București, Editura Academiei R.S.R.

Guțu Romalo 1973 = Valeria Guțu Romalo, Sintaxa limbii române. Probleme şiinterpretări, București, Editura Didactică și Pedagogică.

Hodiș 2006 = Viorel Hodiş, Articole şi studii, vol. I, Cluj-Napoca, Editura Risoprint.

Irimia 1997 = Dumitru Irimia, Gramatica limbii române, Iași, Editura Polirom.

LRC 1978 = Iorgu Iordan, Vladimir Robu, Limba română contemporană, București, Editura Didactică şi Pedagogică.

Neamțu $2004=$ G. G. Neamțu, Dinamica problemelor controversate de morfosintaxă alimbii române. Curs ținut la Facultatea de Litere a UBB din Cluj-Napoca, anul universitar 2003-2004.

Pomian 2013 = Ionuț Pomian, Observații pe marginea conceptelor sintactice de procazși profuncție în sintaxa limbii române, în „Dacoromania”, serie nouă, XVIII, 2013, nr. 2, Cluj-Napoca, p.120-131.

Rovența-Frumușani 2005 = Daniela Rovența-Frumușani, Analiza discursului. Ipoteze și ipostaze, București, Editura Tritonic.

Teodorescu 1974 = Ecaterina Teodorescu, Raportul apozitiv și cel predicativ, în „Analele știinţifice ale Universității «Al. I. Cuza» din Iași”, Iași, 1974, p. 5-8.

Vulişici Alexandrescu 1995 = Maria Vulișici Alexandrescu, Sintaxa limbii române, Oradea, Editura Imprimeriei de Vest. 